\title{
A MATERIALIDADE POÉTICA DE GONÇALO M. TAVARES
}

\author{
GONÇALO M. TAVARES'S \\ POETIC MATERIALITY
}

Paloma Roriz Espínola*

\section{RESUMO}

A arquitetura não raro se empresta a um diálogo com a literatura, como vemos na apropriação que dela já fizeram alguns escritores, como Paul Valéry e João Cabral de Melo Neto, a partir de uma recriação do mito de Anfion. O escritor angolano-português Gonçalo M. Tavares propõe, através de dois textos, Arquitetura, natureza e amor e A estranha casa do senhor Walser, uma aproximação entre o ofício do escritor e o do arquiteto. O objetivo deste artigo é o de mostrar como a proposição de Gonçalo M. Tavares em torno desta aproximação poderia se refletir numa poética baseada na busca de um caráter material da linguagem, mais especificamente nos poemas que compõem o seu livro intitulado 1 , poética a qual se tentará articular as ideias de uma "lucidez emotiva" de Roland Barthes e a de "moção" de Georges Didi-Huberman.

PALAVRAS-CHAVE: arquitetura; materialidade; poesia.

\begin{abstract}
It is not rare that arquitecture opens up to dialog with literature, like it is clearly noticed with the appropriation that some writers have done with it. Such as with Paul Valery's and João Cabral de Melo Neto's with their recriation of Amphion's myth. The anglo-portuguese writer Gonçalo M. Tavares argues on two essays, Arquitetura, natureza e amor and A estranha casa do senhor Walser, an approximation of the duties of a writer and of an arquitect. The purpose of this essay is to demonstrate how Gonçalo M. Tavares' approach reflects on his body of work which is based on the search of the material aspect of language. More especifically on the poems that compose his book entitled 1 , a body of work which attempts to articulate ideas with the "emotional lucidity" of Roland Barthes and the "motion" of Georges Didi-Huberman.
\end{abstract}

KEYWORDS: arquitecture; materiality; poetry. 


\section{LINGUAGEM MATERIAL}

$\mathrm{Na}$ linguagem arquitetônica do arquiteto americano Louis I. Kahn, a luz é um elemento essencial na determinação da ordem e da estrutura de uma construção (TRENTIN, 2013). Essencial na maneira pela qual ela é capturada e trabalhada: seu caráter vertical ou diagonal, por exemplo, sua forma e geometria de abertura, sua concentração em um mesmo ponto, em suma, "a claridade no emprego da técnica da construção" (TRENTIN, 2013, p. 6). A ideia de uma manipulação da luz através da matéria é particularmente interessante na medida em que a participação da luz nas coisas significa que estas podem ser vistas: eis um possível ponto de partida para compreender a relação que o escritor Gonçalo M. Tavares ${ }^{1}$ propõe entre o ofício do escritor e o do arquiteto. Proposta que se apresenta enquanto desejo de acesso a um caráter material da linguagem, na qual a perspectiva arquitetônica parece reger a arte poética exercida pelo escritor - quando o sentido de uma luz arquitetônica se desdobraria em senso de lucidez, de precisão e medida atenta entre as palavras e as coisas.

O objetivo deste artigo é tentar mostrar como esta proposição de Gonçalo M. Tavares em torno de alguns pontos de contato entre a literatura e a arquitetura pode se refletir na poesia do autor, mais especificamente nos poemas que compõem o seu livro intitulado 1 (TAVARES, 2005), volume dividido em oito sessões ou oito pequenos "livros" de poemas, publicado em 2004, em Portugal, e em 2005, no Brasil. O livro se apresenta como uma espécie de microcosmo poético no contexto do conjunto da obra do autor: apesar de outros títulos assimiláveis ao perfil conceitual de um livro de poesia - Livro da dança (TAVARES, 2001), Investigações. Novalis (TAVARES, 2002) e Investigações geométricas (TAVARES, 2005) são alguns exemplos e que irão figurar, na catalogação, ou espécie de "cartografia literária", proposta pelo autor ao final de algumas de suas obras, sob o rótulo de "investigações" -, ou ainda como a epopeia contemporânea Uma viagem a Índia (TAVARES, 2010) ou mesmo Um homem é tonto ou é mulher (TAVARES, 2002) -, o livro 1 (TAVARES, 2005) é o único que recebe propriamente a "etiqueta" de "poesia".

A busca de aspectos convergentes entre o universo literário e o da arquitetura é recorrente no percurso de Gonçalo M. Tavares. Em uma entrevista de 2005, por ocasião do lançamento do livro Investigações Geométricas (TAVARES, 2005), o autor afirma: "É como o desenho de um arquiteto: há um salto quase mortal entre um desenho de uma casa e depois a casa. O que é um livro? Um livro pode ser assemelhado à ideia de um projeto de arquitetura" (LEAL, 2005, p.12). Analogia que será expressa de outra forma, numa síntese própria à poesia, em versos que levam, bem a propósito, o título "Arquiteto": "Depois da arquitectura/ deslocou-se para o invulgar:/ fundou um poema" (TAVARES, 2005, p. 80). A ideia de uma fundação realizada através da linguagem referida nesse pequeno poema, diríamos quase um haikai, parece evocar, de certo modo, o mito de Anfion, o filho de Zeus e Antíope, grande poeta e músico que, com a sua flauta e 
lira, podia mover as pedras - segundo a mitologia grega, para vingar sua mãe maltratada por Dirce, Anfion teria levantado as muralhas de Tebas através do encantamento da sua música.

O mito é retomado por Paul Valéry (1992) em Histoire d'Amphion; depois, sob a influência do escritor francês, será recriado pelo poeta João Cabral de Melo Neto (2008), no poema "Fábula de Anfion", em Psicologia da Composição. Contudo, se no caso dos dois escritores o que se percebe é uma intenção de tomar a arquitetura a partir de uma tradição moderna da visão clássica da linguagem arquitetônica - "como repetição analógica da criação do mundo, cabendo ao arquiteto o papel cosmogônico de demiurgo", como aponta Eucannã Ferraz (FERRAZ, 2000, p. 83) -, Gonçalo M. Tavares, por sua vez, parece se servir dessa arte sólida, não como um recurso de cunho simbólico ou mesmo retórico, mas sobretudo como instrumento conceitual para pensar a linguagem em sua possibilidade de materialidade, de concreção por meio da escrita.

Instrumento que será forjado não sem um entendimento daquilo que distingue o ofício do arquiteto e o do escritor: seu material de trabalho. É o que Tavares lembra: uma das maiores diferenças entre aquele que escreve e aquele que constrói se dá na manipulação do abstrato e do concreto que cada um, respectivamente, opera. Para o autor, uma das maiores violências infringida aos que escrevem reside no fato de seu instrumento de trabalho ser o alfabeto, uma "convenção absoluta" (TAVARES, 2011, p.38). O grande fascínio por uma construção surgirá justamente desse antagonismo face à linguagem: "Quando temos letras estamos no mundo do abstrato, quando temos materiais estamos no mundo do concreto" (TAVARES, 2011, p. 39). Assim, a sua aproximação da arquitetura se revela também como busca de uma medida mais estreita entre a concretude das coisas e as palavras, na qual o desenho ganha um papel importante:

Eu gosto de utilizar palavras que se podem desenhar. Se eu digo a palavra 'cadeira' eu posso desenhá-la. Mas se eu digo a palavra 'efectivamente' eu não posso desenhá-la. Uma das minhas aproximações à arquitetura tem a ver com isto: tento sempre usar palavras que posso desenhar. Se a linguagem é já em si o mundo do abstrato, se eu ainda utilizo palavras muito abstratas, então é uma dupla abstração. A palavra 'efectivamente' é ainda mais afastada do mundo real que as palavras 'copo', 'colher', etc. O que eu tento fazer na minha escrita é uma linguagem material. (TAVARES, 2011, p. 38)

Tal "linguagem material" não deixa de se articular de certo modo à ideia de saber olhar as coisas com os olhos e não através do pensamento abstrato, algo próximo ao que diria Paul Valéry (1998) em seu famoso texto Introdução ao Método de Leonardo da Vinci: "A maioria das pessoas vê aí com muito mais frequência com o intelecto do que com os olhos. Em vez de espaços coloridos, tomam conhecimento de conceitos. (...) Percebem antes de conformidade com um léxico do que de acordo com suas retinas" 
(VALÉRY, 1998, p. 33-35). É fácil encontrar versos de Tavares expressando ideia análoga, como, por exemplo, no poema "A prova da poesia":

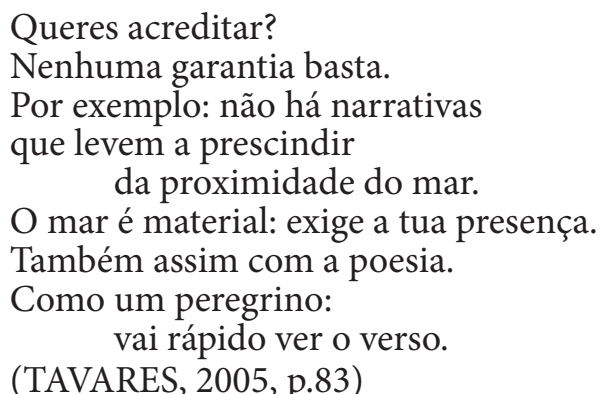

Nenhuma narrativa ultrapassa a realidade, "o mar é material: exige a tua presença", de onde uma provável chave da poética tavariana: "também assim com a poesia", pista ofertada não sem certa ironia: "como um peregrino, vai rápido ver o verso" - quase uma advertência, um lembrete de que a poesia, afinal, não passa de uma questão de fé, de crença, por sempre se encerrar nos limites da linguagem. Mas também, e paradoxalmente, como se somente a ela fosse possível ser tão concreta quanto a própria presença física do mar (similitude sugerida pela deslocação simétrica do quinto e último verso), residindo nisso talvez o seu maior desafio, a sua maior "prova".

Paul Valéry, no texto referido, ainda diz: "Um artista moderno deve perder dois terços de seu tempo em tentar ver o visível, e sobretudo em tentar não ver o que é invisível” (VALÉRY, 1998, p.35). Divisa que parece fazer contato com o desejo de Tavares de falar com o exterior: "Qualquer obra é tanto mais interessante quanto melhor permite a relação com o exterior. As casas têm janelas, portas, tectos, isto é, modos de falar com o exterior" (TAVARES, 2011, p. 36). E ainda com outras reflexões propostas pelo escritor português em torno da mesma questão, desta vez articulada às sensações ou movimentos do corpo, por exemplo, pensamento que parece vir como uma insistência, um modo, uma tentativa de criar uma margem de segurança em relação ao seu instrumento de trabalho, o alfabeto. Em seu livro caleidoscópico Atlas do Corpo e da Imaginação, a propósito de uma questão de Wittgenstein em torno da dificuldade de descrever as sensações, Tavares pergunta:

Que palavras temos para que o outro nos perceba? Ou não há possibilidade de tradução entre estas duas linguagens: a linguagem do corpo, a linguagem dos movimentos e a linguagem que utiliza um alfabeto? (TAVARES, 2013, p. 345, grifo do autor).

De onde conclui mais adiante:

Digamos que há em todo o discurso sobre o corpo um passo de magia que se aceita: algo que existe fisicamente numa linguagem própria é expresso num outro mundo de linguagem - por associações de letras: $d, a$, $c$, etc. Estamos num mundo de tradução mágica, eis o nome mais correcto (traduzir movimentos por palavras). (TAVARES, 2013, p. 346, grifo do autor). 
A partir desse entendimento, os versos do poema "A prova da poesia" (TAVARES, 2005), mencionado acima, parece sugerir que toda tentativa de um registro poético em apreender as coisas do "exterior" - como a materialidade do mar, no exemplo - trará consigo sempre e inevitavelmente um certo truque de "mágica", uma "tradução mágica" que nós, leitores, aceitamos voluntariamente. Consciente disto, o escritor não abdica de um olhar constantemente atento no sentido de conduzir essa "tradução" da forma menos abstrata possível, atenção que exerce não sem uma "presença de leveza" (TAVARES, 2008, p. 8) - expressão usada em outro texto seu sobre arquitetura -, incorrendo a manobras metalinguísticas imprevistas, como no poema "Dansa", em que busca uma coincidência possível entre a letra " $s$ " e a presentificação do movimento corporal:

Tem $S$ a palavra, pois certas curvaturas do mundo exigem alterações de grafia.

O traço imprevisto obriga a parar a meio;

E à paragem insólita chamarás insólito movimento.

E ficarás contente.

(TAVARES, 2005, p. 109)

Assim, não é difícil perceber em muitos dos poemas do livro $1 \mathrm{o}$ verso empregado não só enquanto dispositivo poético/estético, mas também investigativo, no qual a questão acerca dos limites da linguagem, da sua fronteira com a instância "exterior" do mundo, da sua imperfeição e infelicidade, surge como uma intermitência, um consciência que retorna, insiste: "Não há ortografia exacta que possas colocar/ (como um corrector) sobre a tua vida e sobre os amores" (TAVARES, 2005, p. 122); "Repara são dois mundos:/ não é possível atirar água/ à matemática” (TAVARES, 2005, p. 71); "Mas a luz não tem dois lados,/ Ao contrário de uma palavra, qualquer uma,/ Que poderá ser utilizada na pornografia ou/ No supermercado" (TAVARES, 2005, p. 95); "Ninguém escreve como o sol sobre o corpo, ele não utiliza alfabetos ou signos partilháveis" (TAVARES, 2005, p. 211); "Não há definições minuciosas, quando aproximamos/ O olhar daquilo que conhecemos surge o espanto" (TAVARES, 2005, p. 156).

\section{MOÇÃO E MEDIDA}

Contudo, procurar localizar, numa perspectiva filosófica da linguagem, traços de um ceticismo linguístico presente no pensamento de Gonçalo M. Tavares escapa ao propósito deste artigo. Antes, proponho a tentativa de se pensar em como o exercício de uma "linguagem material" (TAVARES, 2011) pode se apropriar e acionar de forma poética particular palavras que se encontram no limiar de uma significação abstrata e ao mesmo tempo concreta, e em que medida, nesta forma, que aqui dou o nome de materialidade poética, poderiam se articular a busca de uma "lucidez emotiva", na expressão de Roland Barthes (2002) - encontrada na obra $O$ neutro: anotações de aulas e seminários ministrados no Collège de France - e a percepção de deslocamentos afetivos ínfimos, ou "moções", seguindo um 
pensamento de Georges Didi-Huberman (2013), com base em seu livro Quelle émotion! Quelle émotion ?. Para tanto, uma palavra, recorrente nos textos do livro 1 , será tomada aqui como fio condutor: a palavra "coração". Segue um poema da sessão Livro dos Ossos:

Como se bêbado nas cicatrizes: olhava para o espelho e elas mexiam-se. É preciso parar os olhos.

Ossos redondos, tornados maduros com o sol. Caem.

Decidiu não mudar. Não perder a forma como os fósforos.

Sobretudo não diminuir o tamanho da inteligência, da cabeça.

Resistir ao fogo, ao tempo que come a madeira.

No entanto o pátio do desejo: vazio, varrido por cavalos rápidos: os dias.

- Envelheço.

Referia-se aos órgãos, ao coração por exemplo.

(TAVARES, 2005, p. 58)

O senso de lucidez, de consciência, insinua-se por meio dos verbos de entonação injuntiva: "É preciso", "Não perder", "Sobretudo não diminuir", "Resistir", todos indicando uma reação face ao tempo, já anunciada no primeiro verso através da alusão às cicatrizes. Diante do tempo, figurado pela imagem do sol, os ossos, como as frutas, tornam-se maduros e caem. Mas se os ossos caem, assim como os fósforos perdem a forma com o fogo, a inteligência pode, ela, resistir lá onde a maturidade dos ossos sugere também a ideia de uma sabedoria adquirida, capaz de sustentar o "tamanho da inteligência", da cabeça, da consciência: sua medida, seu estatuto de defesa possível diante do tempo que, como o fogo, come a madeira, a matéria. Porém, a conjunção adversativa previne acerca da presença inelutável do corpo: "No entanto, o pátio do desejo: vazio", e aqui a metáfora súbita retoma a ideia do tempo: "varrido por cavalos rápidos: os dias". É então que o travessão descarrega a conjugação de um verbo que ressoa sozinho, na primeira pessoa, compondo a linha de um verso: “- Envelheço". O preço a pagar por não mudar, por sustentar a estatura da cabeça, da inteligência, é o de esvaziar o desejo e, portanto, justamente por isso - paradoxo incontornável -, de envelhecer o coração, mencionado no último verso, não sem alguma ironia: o coração enquanto um órgão como outros do corpo, "por exemplo".

Na perspectiva retórica do "neutro", que ganha contorno mais definitivo nas notas e fichas do curso "O Neutro" (BARTHES, 2002), proferido no Collège de France, durante os anos 1977-1978, Roland Barthes recorre, em meio a outras tantas figuras, a uma que pode interessar particularmente como chave de leitura para a poética tavariana: a figura da "consciência"2. A proposição de Barthes consiste em tomar a consciência como sendo ela mesma uma droga "isso sob condições simples de excesso $\rightarrow$ consciência excessiva, a hiperestesia consciencial” (BARTHES, 2003, p. 199). Duas formas dessa hiperconsciência são então consideradas: a hiperconsciência intelectualista, completamente capturada pela sua própria reflexividade e 
esta mesma hiperconsciência "como algo que se eleva sobre fundo de afeto, pondo em cena o afeto, a 'sensibilidade' viva" (BARTHES, 2003, p. 199). Esta segunda forma, a consciência excessiva a qual se junta o elemento da afetividade e da emotividade, leva a perceber uma contradição entre a conjunção do intelecto e a do afeto. Roland Barthes menciona então toda uma tradição clássica, racionalista (Descartes, Pascal, Bossuet, Malebranche, etc.) que desconfia do "coração", do imaginário, associado ao erro e ao falso. É uma tradição à qual a filosofia de Giambattista Vico, por exemplo, orientada na direção de uma teoria geral da imaginação, viria se opor colocando em relevo o conhecimento imaginativo, a soberania da sabedoria poética como "forma primeira de todo conhecimento" (BARTHES, 2003, p. 210). De uma "lucidez emotiva" (BARTHES, 2003, p. 211) sobrevém então o paradoxo: ou eu estou emocionado, afetado, ou eu estou calmo, eu meço, eu tranquilizo. Assim, seria necessário uma hiperconsciência do "tênue afetivo", do "parcelar ínfimo da emoção" (BARTHES, 2003, p. 212).

O poema citado acima parece, de certo modo, tocar a contradição barthesiana. A busca de uma "lucidez emotiva" é, de fato, possível? Corresponderia ela a um "neutro" inacessível, quimérico, sensação permanente de enigma (BARTHES, 2003, p.211)? Os versos de Tavares apontam para o equilíbrio tênue que essas duas instâncias, a lucidez e a emotividade (representada no poema pela imagem do "desejo") podem sustentar entre si. A imagem do "coração" retorna ainda em outros poemas, sempre em torno de uma observação, de uma inquirição acerca de sua fragilidade, de sua força, de seus movimentos diante do tempo ["Os dias avançam, e o coração, por vezes,/ é ainda mais veloz" (TAVARES, 2005, p. 20)]; face ao retraimento ["Amava o pai, mas o coração é assim/ (a lei da sobrevivência):/ esconde-se quando o querem matar" (TAVARES, 2005, p. 21)]; à interferência [“O coração necessita de afinação como os rádios./ (...) Mas qual o botão que afina o coração?" (TAVARES, 2005, p. 38)]; à insensibilidade ["E ao sentir a minha memória lembrar-se do coração,/ esbocei um sorriso, satisfeito" (TAVARES, 2005, p. 23)]; à possibilidade de redenção ["Felizmente, fomos salvos/ pelo coração" (Tavares, 2005, p. 100)]; e de ligação ["Dois amigos aproximam o rosto/ para aproximarem os corações" (TAVARES, 2005, p. 27)].

Em seu livro Quelle émotion! Quelle émotion ?, Georges Didi-Huberman (2013), apoiando-se em uma definição de Aristóteles, propõe uma leitura do fenômeno da emoção a partir de sua ligação com a palavra "patético", derivação da palavra grega pathos, "quer dizer a 'paixão' ou a impossibilidade de agir” (DIDI-HUBERMAN, 2013, p. 25), por oposição à palavra logos e à razão:

A emoção seria então um impasse: impasse da linguagem (quando, emocionado, eu fico quieto, não conseguindo mais achar minhas palavras); impasse do pensamento (quando, emocionado, eu perco todos os meus recursos); impasse do ato (quando, emocionado, eu fico com os braços soltos, incapaz de me mover como se uma serpente invisível me imo- 
bilizasse). (...) Um impasse, é quando não se passa: é uma noção negativa. Muitos filósofos teriam, assim, falado da emoção como de uma coisa somente negativa.

(DIDI-HUBERMAN, 2013, p. 27, tradução nossa).

O autor nos mostra como, inversamente, alguns filósofos renderam dignidade ao pathos face ao logos: Hegel, Nietzsche, Henri Bergson, Jean-Paul Sartre, Maurice Merleau-Ponty ou Gilles Deleuze, são alguns exemplos. E é sublinhando o pensamento de Bergson - a saber, as emoções consideradas não como um impasse, mas como gestos ativos -, que Didi-Huberman recorda o que a palavra diz em si mesma: "uma emoção, não é uma e-moção, quer dizer uma moção um movimento, que consiste em nos colocar fora de $(e-, e x)$, fora de nós mesmos?" (DIDI-HUBERMAN, 2013, p. 30, tradução nossa). À luz desta proposição, é interessante perceber em que medida certos poemas do livro 1 (TAVARES, 2005) apresentam um sujeito poético que parece tentar capturar os sinais, os vestígios, as pistas desses movimentos afetivos, dessas "moções", dessas comoções por vezes veladas, sub-reptícias, como no poema "As duas mulheres", no qual a palavra "coração" reaparece:

Falam, mas pouco. Pensam em tudo menos nas palavras: ocupam parte da tarde não deixando cair a outra. Nada de entusiasmos: cada uma suporta-se suportando. Nenhum gozo; passaram já a idade dos risos por nada, agora, frente a frente, têm só o vazio, e uma, mais medrosa, o tabaco.

Pose de quem aguarda com a vitória garantida, mas não.

Dirigido para o céu, o cigarro, e basta.

Chegará, porventura, lá acima o fumo;

Os afectos, permanecem sólidos: terrestres.

Queriam o dia diferente, isso é claro,

não têm coragem, no entanto, para - separadas uma da outra

exibirem o instinto predador ou a fragilidade; a procura.

Decidem interromper o que nem sequer começou;

a mais tensa prepara o corpo, levanta-se;

a outra segue-a.

Saem as duas, mas não lado a lado.

Uma e outra tapam tanto o coração que nem sabem ser tristes;

e só dos corajosos é a tristeza, dos que olham para cima.

(TAVARES, 2005, p 14)

O texto é vazio de acontecimentos: o tédio, a lassidão de duas mulheres desencantadas nas circunstâncias de um encontro fortuito. Nenhum entusiasmo, nenhuma vibração, nenhum riso. Mas a cena, desnudada por versos prosaicamente descritivos, revela a intensidade suspensa que o vazio descrito é capaz de encerrar. O narrador dá a ver então, na ausência aparente de qualquer tipo de afetação nas duas mulheres, os indícios de uma emoção mais funda, mais subterrânea: a desistência, a renúncia, o medo diante da vida, o coração tão coberto que mesmo a tristeza não existe mais. Os 
afetos são rasteiros, terrestres, sem altitude, sem elevação; ao céu somente a fumaça do cigarro. Didi-Huberman fala da manifestação da emoção como de uma tomada de risco, a de expor a sua própria fraqueza, sua impotência, sua "incapacidade em 'fazer face" (DIDI-HUBERMAN, 2013, p. 43), como de um engajamento, um ato de honestidade, e aqui, pode-se dizer, da impotência em se confrontar com o céu, com as coisas elevadas, com tudo aquilo que nos ultrapassa: a tristeza enquanto um ato de coragem, o ato de olhar para o alto, para além, fora de nós mesmos.

Outros exemplos afluem, particularmente na primeira sessão, intitulada Observações, em que, de maneira mais evidente (não é raro encontrar os verbos "percebo", "noto", "vejo"), surgem versos denunciando as nuances de pequenos movimentos afetivos percebidos nos outros, como entre duas jovens ["Aguardam calmas, quase neutras, o desejado alvoroço/ (...) Não são audazes em demasia; não mostram ansiedade/ (talvez exista, não sei)" (TAVARES, 2005, p. 12)]; nos gestos de um rapaz em um café ["Afinal não procura emprego; o Desejo encontrou-o,/ desocupado" (TAVARES, 2005, p. 13)]; entre duas velhas ["Voltarão, mais tarde, a casa e às orações,/ depois de desejarem intimamente que os filhos se tornem ricos/ e que a amiga morra primeiro" (TAVARES, 2005, p. 15)]; nos esforços de um viúvo ["Antes a ambição fazia-o levantar-se,/ agora, quase se podia jurar, ser o cachimbo que o mantém em pé,/ agarrado ao ar como a nada" (TAVARES, 2005, p. 16)]; ou ainda na apreensão de uma jovem ["O medo de ser de novo abandonada assustou a carne/ até aos pulsos" (TAVARES, 2005, p. 17)]; e finalmente na mulher prestes a cometer o adultério ["De regresso a mim penso no que é o destino,/ e no que é o tempo,/ e sei, tenho uma certeza clara: aquela mulher vai sofrer" (TAVARES, 2005, p. 31)]. A sobriedade dos versos - em estilo econômico, por vezes lacônico, direto, com as construções simples das frases, muitas vezes seguindo a estrutura sujeito/verbo/objeto -, revela uma observação atenta aos detalhes, um olhar minucioso capaz de apreender a gradação por vezes sutil desses movimentos afetivos descritos -, quando é possível então retomar a ideia de uma "lucidez emotiva", proposta por Roland Barthes, transposta aqui para o registro privilegiado do poeta. Como se fosse possível à poesia exprimir uma "sensibilidade consciencial" (BARTHES, 2002, p. 213), como se a ela fosse dada a tarefa de procurar, sob a luz fria de um olhar lúcido, a fração mínima da emoção.

Recuperando a aproximação que Tavares propõe entre o trabalho da escrita e o da arquitetura, é no texto Arquitectura, Natureza e Amor que o autor afirma:

$\mathrm{O}$ arquitecto é aquele que procura os tamanhos verdadeiros e belos das coisas e a sua relação de maior altitude. Não basta ao arquitecto dominar os concretos valores do peso das coisas e da distância entre elas (paredes, vazios, funções, tectos, vazios), o arquitecto deverá também saber manipular os materiais do pressentimento que são a base do ofício do poeta e do artista.

(TAVARES, 2008, p. 5, grifo do autor). 
É interessante se ater aqui à significação da palavra "pressentimento": "ato de sentir antecipadamente, mais pela emoção do que pela razão, a ocorrência de um fato futuro" (HOUAISS, 2001, p. 2293). A este significado se ligaria então a ideia de "instinto" apontada também pelo autor: "os materiais do pressentimento surgem no mundo humano apoiados pelo instinto" (TAVARES, 2008, p.5); o instinto: "esquecimento súbito, e com consequências, da racionalidade" (TAVARES, 2008, p.6). É um entendimento que parece retificar as balizas de uma poética própria ao escritor, de uma materialidade poética, mais propriamente, na qual a tentativa de tocar uma "lucidez emotiva" (Barthes, 2002, p.211) - uma hiperconsciência da agudeza afetiva, do "parcelar ínfimo da emoção", dos "materiais do pressentimento" ofertados pelas "moções" (DIDI-HUBERMAN, 2013, p.30) ou movimentos afetivos mínimos -, se reitera a cada poema, quando a palavra "pressentimento" pode se avizinhar igualmente da palavra "premonição": aviso, presságio, advertência, o que remete de alguma forma ao ceticismo de Tavares diante da precariedade da linguagem, à sua desconfiança e consciência da fissura instransponível entre a linguagem e o mundo, à busca de uma dicção neutra, de cunho crítico, investigativo, voltada sobretudo para o pensamento. E talvez seja interessante também lembrar que o escritor já declarou por diversas vezes uma ligação importante com o pensamento estoico, mais precisamente o de Sêneca ${ }^{3}$.

Retomo, então, a ideia com a qual abri este artigo: o papel fundamental da luz para a arquitetura, a ideia de que o trabalho do arquiteto é um trabalho de manipulação da luz, a forma como é apreendida, trabalha$\mathrm{da}$, direcionada, através dos materiais concretos, dos valores dos pesos, da distância entre as coisas. Talvez, então, seja propício entender essa articulação de Gonçalo M. Tavares entre os dois ofícios como uma tentativa de advertir que o trabalho da literatura é fundamentalmente esse: o de saber manipular a luz, no sentido de uma lucidez, de uma consciência, de um entendimento do que é essencial e do que é insignificante, sem, no entanto, jamais abrir mão do instinto, da premonição, do pressentimento.

\section{REFERÊNCIAS BIBLIOGRÁFICAS}

BARTHES, Roland. O neutro: anotações de aulas e seminários ministrados no Collège de France, 1977-1978. Trad. Ivone Castilho Benedetti. São Paulo: Martins Fontes, 2003.

DIDI-HUBERMAN, Georges. Quelle émotion ! Quelle émotion ? Montrouge: Bayard Éditions, 2013.

FERRAZ, Eucanaã. Anfion, Arquitecto. Paisagem Tipográfica - Homenagem a João Cabral de Melo Neto. Colóquio/Letras. Lisboa, ${ }^{\circ}$ 157/158, p. 81-98, jul-dez. 2000.

HOUAISS, Antônio. Dicionário Houaiss da Língua Portuguesa. Rio de Janeiro: Instituto Antônio Houaiss, 2001. 
LEAL, Filipa. O olhar litérario de Gonçalo M. Tavares sobre a geometria. Das Artes das Letras. Lisboa, n 19, p. 12-13, maio. 2005.

NETO, João Cabral de Melo. Psicologia da composição. In: Poesia Completa e Prosa. Rio de Janeiro: Nova Aguilar, 2008.

STUDART, Júlia Vasconcelos. A literatura de Gonçalo M. Tavares : investigação arqueológica e um dançarino sutil nas esferas O Bairro e o Reino. Tese de doutorado, UFSC/Programa de Pós-graduação em Literatura, 2012.

TAVARES, Gonçalo M. Livro da dança.Lisboa: Assírio \& Alvim, 2001. Investigações. Novalis. Algés: Difel, 2002.

. 1. Rio de Janeiro: Bertrand Brasil, 2005.

Investigações geométricas. Porto: Fundação Ciência e Desenvolvimento, 2005.

. Arquitetura, natureza e amor. Opúsculo, Porto, $\mathrm{n}^{\circ} 14, \mathrm{p}$. 3-10, jul. 2008.

. Uma Viagem à Índia - Melancolia contemporânea (um intinerário). Alfragide: Editorial Caminho, 2010.

A estranha casa do Senhor Walser. In: GUERREIRO, Julián Santos, TAVARES, Gonçalo M., MENDES DA ROCHA, Paulo. Pensar a casa. Conferências da Casa, v. 1, p. 29-43. Matosinhos: Associação Casa da Arquitectura, 2011.

Atlas do corpo e da imaginação. Lisboa: Caminho, 2013.

TERRON, Joca. Entrevista: Gonçalo M. Tavares 'Ler para ter lucidez'. Entrelivros, n $^{\circ} 29$, p. 12-14, set. 2007.

TRENTIN, Annalisa. Une mémoire revisité. Cosa Mentale, Paris, $\mathrm{n}^{\circ}$ 11, p. 6-7, set, 2013.

VALÉRY, Paul. Introdução ao Método de Leonardo da Vinci. Trad. Geraldo Gérson de Souza. São Paulo: Editora 34, 1998.

. Euvres Complètes. Paris : Éditions Gallimard (Collection Folio/Essais), 1992.

Recebido para publicação em 31/05/2015

Aprovado em 28/08/2015

\section{NOTAS}

* Mestre em Estudos Lusófonos pelo Departamento de Estudos Ibéricos e Latino-americanos na Université Sorbonne Nouvelle - Paris 3. Doutoranda na Universidade Federal Fluminense, Programa de Pós-Graduação em Estudos de Literatura. 
${ }^{1}$ Nascido em 1970, em Angola (Luanda), Gonçalo M. Tavares muda-se ainda pequeno para Portugal. Sua primeira publicação data de 2001 (Livro da dança). Com cerca de mais de trinta livros publicados - entre romance, conto, poesia, teatro e ensaio -, recebeu os mais importantes prêmios em língua portuguesa (Portugal Telecom 2007, Prêmio José Saramago 2005, Prêmio LER/Millennium BCP 2004, entre outros).

${ }^{2}$ Sobre o caráter neutro da obra de Gonçalo M. Tavares, remeto o leitor a Studart (2012).

${ }^{3}$ Em uma entrevista Tavares afirma: "Quanto ao resto, eu considero-me muito filho de Sêneca. As Cartas a Lucílio, de Sêneca, é talvez o livro que mais marcou a minha vida. Tenho uma parte estoica: guardo alguma distância em relação ao que vai acontecendo" (Terron, 2007, p. 12). 